\title{
ORIGINAL ARTICLE Validity of one-repetition maximum predictive equations in men with spinal cord injury
}

\author{
F Ribeiro Neto, P Guanais, E Dornelas, ACB Coutinho and RRG Costa
}

\begin{abstract}
Study design: Cross-sectional study.
Objectives: The study aimed (a) to test the cross-validation of current one-repetition maximum (1RM) predictive equations in men with spinal cord injury (SCl); (b) to compare the current 1RM predictive equations to a newly developed equation based on the 4- to 12-repetition maximum test (4-12RM).

Setting: SARAH Rehabilitation Hospital Network, Brasilia, Brazil.

Methods: Forty-five men aged 28.0 years with SCI between $\mathrm{C} 6$ and L2 causing complete motor impairment were enrolled in the study. Volunteers were tested, in a random order, in 1RM test or 4-12RM with 2-3 interval days. Multiple regression analysis was used to generate an equation for predicting 1RM.

Results: There were no significant differences between 1RM test and the current predictive equations. ICC values were significant and were classified as excellent for all current predictive equations. The predictive equation of Lombardi presented the best Bland-Altman results $(0.5 \mathrm{~kg}$ and $12.8 \mathrm{~kg}$ for mean difference and interval range around the differences, respectively). The two created equation models for 1 RM demonstrated the same and a high adjusted $R^{2}(0.971, P<0.01)$, but different SEE of measured 1 RM (2.88 $\mathrm{kg}$ or $5.4 \%$ and $2.90 \mathrm{~kg}$ or $5.5 \%)$.

Conclusion: All 1RM predictive equations are accurate to assess individuals with $\mathrm{SCl}$ at the bench press exercise. However, the predictive equation of Lombardi presented the best associated cross-validity results. A specific 1RM prediction equation was also elaborated for individuals with SCl. The created equation should be tested in order to verify whether it presents better accuracy than the current ones.
\end{abstract}

Spinal Cord (2017) 55, 950-956; doi:10.1038/sc.2017.49; published online 9 May 2017

\section{INTRODUCTION}

Strength training is recommended for participation in physical activities and rehabilitation programs for patients with spinal cord injury (SCI). It is associated with independence in and functional acquisition of daily activities. ${ }^{1-3}$ In this population, strength facilitates wheelchair propulsion, pressure relief and transfers. ${ }^{4-6}$ It is associated with increased cardiovascular capacity, ${ }^{7,8}$ exercise tolerance, ${ }^{8}$ reduction in shoulder pain ${ }^{2}$ and improved health. ${ }^{1}$ During maximal or submaximal aerobic tests, the main limitation is related to strength and local muscle fatigue. ${ }^{4,9}$

Strength is reduced by disuse that accompanies the aging process. ${ }^{10}$ In addition, individuals with SCI are more sedentary $9,11,12$ and less likely to perform any physical activity. ${ }^{13,14}$ Consequently, increases in fat percentage and decreases in strength and muscle mass are common characteristics of SCI, especially during the first 3 months after trauma. ${ }^{15-17}$ Gorgey and Shepherd reported that atrophy contributes to changes in body composition and to increases in glucose intolerance, type II diabetes, hyperlipidemia, osteoporosis, metabolic syndrome and cardiovascular diseases. ${ }^{18}$

An accurate assessment of maximum strength is important to determine the workloads that should be used in the design of training programs. ${ }^{19}$ Many resistance programs are created using percentages of the maximum load. Therefore, correct determination of the relative load is essential for correctly prescribing training. These values comprise one of the main variables used to determine training objectives, such as strength, hypertrophy, power and local muscle endurance. $^{20,21}$

One way to determine workload is by using the one-repetition maximum (1RM) test to prescribe workout intensity. The 1RM test is the maximum weight lifted at one time in a controlled manner; it is considered a benchmark in dynamic strength evaluation. ${ }^{19,22-24}$ However, several authors have reported difficulties in test execution and increased risk of injury depending on the population. ${ }^{19,25-27}$ An alternative assessment involves estimating the maximum load through multiple-repetition maximum assessments such as 5RM or 10RM. ${ }^{23,24,27}$ The results found using these tests are variables used for $1 \mathrm{RM}$ predictive equations. These equations have been developed for different populations and situations involving trained and untrained individuals, ${ }^{25,27-29}$ both sexes, ${ }^{19,27-29}$ different types of strength machines ${ }^{30,31}$ and the elderly. ${ }^{32}$ Some of the most commonly used 1RM predictive equations are from Epley, ${ }^{33}$ Lombardi, ${ }^{34}$ O'Connor et al., ${ }^{35}$ Mayhew et al., ${ }^{36}$ Brzycki $^{37}$ and Baechle and Groves. ${ }^{38}$ Regarding motor impairment, only one study involving individuals with SCI has been conducted. ${ }^{26}$ Schwingel et al. found 
Table 1 Subjects demographics and descriptive statistic of strength variables for tetraplegia, high paraplegia and low paraplegia groups

\begin{tabular}{|c|c|c|c|c|}
\hline & $T P$ & $H P$ & $L P$ & Total \\
\hline Age (years) & $28.0(26.0-32.0)$ & $28.0(21.0-31.0)$ & $26.0(24.0-32.0)$ & $28.0(24.0-31.5)$ \\
\hline Body mass (kg) & $66.7( \pm 12.0)$ & $74.0( \pm 18.1)$ & $71.6( \pm 15.2)$ & $70.8( \pm 15.2)$ \\
\hline Height $(\mathrm{cm})$ & $175.0( \pm 4.5)$ & $174.4( \pm 4.6)$ & $175.7( \pm 5.9)$ & $175.0( \pm 4.9)$ \\
\hline BMI $\left(\mathrm{kg} \mathrm{m}^{-2}\right)$ & $21.7( \pm 3.6)$ & $23.9( \pm 5.2)$ & $23.1( \pm 4.2)$ & $22.9( \pm 4.4)$ \\
\hline \multicolumn{5}{|l|}{ Strength variables } \\
\hline $1 \mathrm{RM}(\mathrm{kg})$ & $33.8( \pm 17.0)$ & $53.4( \pm 12.6)^{a}$ & $57.8( \pm 10.2)^{a}$ & $48.3( \pm 16.9)$ \\
\hline $1 \mathrm{RM} / \mathrm{BM}$ & $0.51( \pm 0.26)$ & $0.74( \pm 0.14)^{a}$ & $0.83( \pm 0.15)^{a}$ & $0.69( \pm 0.23)$ \\
\hline 4-12RM (kg) & $21.1(6.1-47.1)$ & $43.1(25.1-67.1)^{a}$ & $47.1(33.1-73.1) a$ & $43.1(32.1-47.1)$ \\
\hline 4-12RM (rep) & $6.0(4.0-11.0)$ & $8.0(5.0-11.0)^{a}$ & $6.0(5.0-10.0)$ & $7.0(5.0-9.0)$ \\
\hline
\end{tabular}

Abbreviations: 1RM, one-repetition maximum test; 4-12RM, 4- to 12-repetition maximum test; BM, body mass; BMI, body mass index; HP: high paraplegia group; LP, low paraplegia group; TP, tetraplegia group; TSI, time since injury; $\sum \mathrm{SF}$, skinfolds sum; \%Fat, fat percentage.

Age, time since injury and 4-12RM outcomes are exhibited by median (percentiles 25 and 75 ). Other variables are shown by mean (s.d.).

asignificant difference compared to TP $(P<0.016)$

a good correlation between the 1RM test and predictive equation of 1RM using the 12-repetition maximum (12RM) test for the bench press and T-bar row machine for Paralympic rowers. ${ }^{26}$ However, no individual in the sample had a diagnosis of SCI.

The present study aimed (a) to test the cross-validation of current $1 \mathrm{RM}$ predictive equations in adults with SCI; (b) to compare the current $1 \mathrm{RM}$ predictive equations to a specific developed equation based on the 4- to 12-repetition maximum test (4-12RM) in individuals with SCI; and c) to verify whether relative and absolute 1RM loads are similar between injury levels. Considering correct posture stabilization and positioning adaptations in the test, the hypothesis of this study was that current predictive equations will not be applicable for individuals with SCI and a newly developed one, based on the specific population, will have a positive and significant correlation with the 1RM test.

\section{METHODS}

\section{Participants}

In total, 45 patients with SCI were consecutively enrolled in the study. They were participants in a rehabilitation program of the Rehabilitation Hospitals and were recruited during the second week of rehabilitation. Before the rehabilitation program, the patients were not participating in physical activities. The data collection period was February 2013 to April 2016.

Patients unable to participate in the rehabilitation program, with a history of metabolic disorders and with a history of cardiovascular, cardiac, or orthopedic surgery that would restrict their ability to execute tests or perform correct exercise biomechanics, were excluded from the selection process. Therefore, the following inclusion criteria were used: male (older than 18 years), diagnosis of traumatic SCI, complete motor lesion (ASIA Impairment Scale [AIS] grade A or B), ${ }^{39,40}$ clinical stability and wheelchair use. The International Standards for Neurological Classification of Spinal Cord Injury published by American Spinal Injury Association (ASIA) was used to assess motor level of the individuals with spinal cord injury by a trained physiotherapist. ${ }^{39,40}$

Participants were stratified into three groups for analysis: tetraplegia group (TP; C6 to C8), high paraplegia group (HP; T1-T6), and low paraplegia group (LP; T7-L2). The first group (TP) had upper limb impairment, including reduced hand grip strength. Therefore, the assistance equipment was used to fix the hand press over the bar. The division between TP and paraplegia groups was in accordance with the ASIA tetraplegia classification. ${ }^{39,40}$ The TP and HP groups had cardiovascular dysfunctions due to autonomic nervous system alterations and trunk instability mainly due to innervations of the abdomen (intercostal nerves T7 to T11). All groups had reduced or absent strength in the lower limbs.

Sample demographics are presented in Table 1.

\section{Procedures}

Before testing, participants were informed about all procedures and were instructed regarding the execution techniques.

Body composition assessment. On the first day of testing, participants underwent a body composition assessment. During this evaluation, body mass $(\mathrm{BM})$, lean body mass (LBM), height $(\mathrm{cm})$, skinfold sum $\left(\sum \mathrm{SF}\right)$ and body fat percentage using the skinfold protocol were measured. ${ }^{41}$ Brachial biceps, brachial triceps and subscapular and suprailiac sites were used in the Durnin and Womersley skinfold equation for body fat percentage prediction. ${ }^{16,41-44}$ Pectoral, mid-axillary, abdominal, thigh and leg sites were also measured to calculate the skinfold sum.

Adaptation and familiarization. To adapt to weight training and to familiarize participants with the test, four exercise sessions were performed 2 weeks before the assessments. ${ }^{25,45}$ Each session was performed with a minimum interval of $48 \mathrm{~h}$ (Figure 1).

During the first week, two sessions of two series of 12-15 repetitions to maximum with intervals of 1-2 min were performed for neuromuscular adaption. The exercises were performed using the following cable machines: bench press, peck deck, pull down, seated row and triceps pushdown. Dumbbells were used only during biceps exercises.

During the second week, two sessions of three series of 6-10 repetitions to maximum of bench press with a bar with intervals of 2-3 min were performed for test familiarization. Seated row, triceps pushdown and dumbbell biceps exercises were retained.

Assistance equipments such as bandages and neoprene strips were used for trunk and leg stabilization of all participants at the bench. For individuals with tetraplegia, assistance equipment was used to fix the hand press over the bar. The same adaptations were used during the familiarization phase and maximum strength tests.

Maximum strength tests. Maximum strength tests (1RM and 4-12RM) were executed using bench press exercises on a bench that was $26 \mathrm{~cm}$ wide and $123 \mathrm{~cm}$ long. This exercise is considered the best isolated assessment to predict total dynamic strength, ${ }^{22}$ upper limb strength ${ }^{19}$ and loads for tests and exercises. ${ }^{19}$ The barbell is $3.1 \mathrm{~kg}$ and $1.84 \mathrm{~cm}$, and weights range from 0.5 to $20 \mathrm{~kg}$. Patients were instructed to refrain from eating or smoking for $3 \mathrm{~h}$ before the tests, to not perform strenuous exercise for $6 \mathrm{~h}$ before the tests and to empty their bladder before the tests. 
Bench press exercises were performed in the supine position with the participant's feet on the ground. The hips and legs of the participants were stabilized with straps. Each repetition had four phases as follows: (1) extended elbows and hands holding the bar; (2) elbow flexion and horizontal shoulder extension (eccentric phase for approximately $2 \mathrm{~s}$ ); (3) light touch of the barbell at the mesosternal point; and (4) elbow extension and horizontal shoulder flexion (concentric phase). During the first repetition, two physical educators put the barbell in the participant's hands. Grip width was measured with elbows at 90 degrees and arms parallel to the ground. The mesosternal point was marked before execution, and no physical support was allowed during valid repetitions.

The maximum strength tests were assessed by the same tester and were performed randomly with 48- and 72-h intervals to avoid accumulated fatigue $^{25,28,29}$ (Figure 1).

One-repetition maximum test. Before the 1RM test, participants performed a warm-up of 5-10 repetitions with $50 \%$ of the perceived maximum load. After $1 \mathrm{~min}$ of rest, 3 to 5 repetitions with $70 \%$ of the perceived maximum load were performed. ${ }^{22-24}$ Perceived maximum load was estimated based on researcher and participant perceptions regarding the four sessions of adaption and familiarization performed previously.

After the warm-up, the participant rested for $2 \mathrm{~min}$, the load was increased and the exercise was performed. After a 5-min interval, the load was increased or decreased to allow only one repetition. The maximum number of attempts

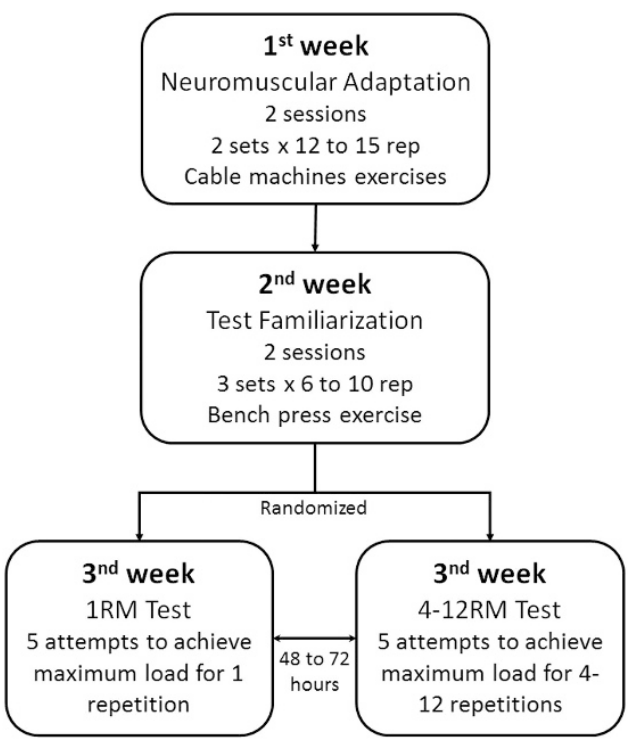

Figure 1 Protocol for $1 \mathrm{RM}$ predictive equation based on $4-12 \mathrm{RM}$ test. $1 \mathrm{RM}$, one-repetition maximum test; 4-12RM, four to twelve repetition test; Rep: repetitions. during the same session was five according to the procedure described in the literature $^{22-24}$ (Figure 1).

Four- to twelve-repetition maximum test. The same warm-up protocol for the $1 \mathrm{RM}$ test was performed. The initial load used was $\sim 80-90 \%$ of the maximum perceived load. ${ }^{22-24}$ The participants were instructed to perform the most possible lifts until concentric movement failure. The number of repetitions was supposed to be at least 4 and at most 12. Otherwise, a new attempt was performed after $5 \mathrm{~min}$ of rest. The load was decreased if the repetition number was less than 4 or increased if it was more than 12. The maximum number of attempts during the same session was five according to the procedure described in the literature. ${ }^{22-24}$ The load and repetitions were inserted at the following current predictive equations:

- Eq1: Epley $B^{33}: 1 \mathrm{RM}=(0.0333 \times$ load $) \times$ reps $\times$ load

- Eq2: Lombardi $\mathrm{P}^{34}: 1 \mathrm{RM}=\left(\mathrm{reps}^{1}\right) \times$ load

- Eq3: O'Connor R et al. ${ }^{35}: 1 \mathrm{RM}=\operatorname{load} \mathrm{x}[1+(0.025 \mathrm{x}$ reps $)]$

- Eq4: Mayhew J et a ${ }^{36}: 1 \mathrm{RM}=100 \times \operatorname{load} /(52.2+41.9 \times \exp (-0.055 \times$ reps $))$

- Eq5: Brzycki $\mathrm{M}^{37}: 1 \mathrm{RM}=\left(\operatorname{load} \times(1.0278-(0.0278 \times \text { reps }))^{-1}\right.$

- Eq6: Baechle R and Groves $\mathrm{E}^{38}: 1 \mathrm{RM}=\operatorname{load} \times((0.0375 \times$ reps $)+0.978)$

\section{Statistical analysis}

A sample of 45 patients was required to perform linear multiple regression analysis (fixed model) considering an effect size of 0.35 (average), $\alpha$ of $5 \%$ and power $(1-\beta)$ of $90 \%$ with three predictors.

To assess the cross-validation, the intraclass correlation coefficient (ICC) with Bland-Altman plot was used to compare the current predictive equations with IRM test. The ICC was classified based on Cicchetti standards as follows: below 0.40 -level of clinical significance is poor; 0.40 to 0.59 -fair; $0.60-0,74$ - good; and 0.75-1.00-excellent. ${ }^{46}$ Confidence intervals of $95 \%$ (95\% CI) was used between comparisons.

To compare groups, one-way analysis of variance (ANOVA) with the Bonferroni post hoc test $(P<0.016)$ was used when normal distribution was detected. The significance level was set at 0.016 to a more conservative analysis ( 0.05 divided by three comparison two by two). The Kruskal-Wallis test and Mann-Whitney post hoc test were used to compare non-normal variables.

Stepwise multiple regression analysis was used to generate specific equations for predicting 1RM load in individuals with SCI. These regression analyses maintain or remove the predictor variables for the best equation models. Three clusters of three variables were established. Each cluster was created as follows: cluster 1 (weight for 4-12RM), cluster 2 (repetitions for 4-12RM), cluster 3 (time since injury, body mass, body mass index, $\sum$ SF, injury level, time since injury and age). Each variable from cluster 3 was entered into one stepwise regression with three predictors to determine 1RM load. Weight and repetitions for 4-12RM were maintained at all generated equations because these variables were reported at most of previous prediction equations. Injury level was considered as a dummy variable, indicating which group (TP, HP and LP) was used for a particular observation. The accuracy of the 1RM prediction was quantified using R-square and the standard error of the estimate.

Table 2 One-repetition maximum test (1RM) results and the current predictive equations based on multiple maximum repetitions (kg)

\begin{tabular}{|c|c|c|c|c|}
\hline & $T P$ & $H P$ & $L P$ & Total \\
\hline $1 \mathrm{RM}$ & $33.8( \pm 17.0)$ & $53.4( \pm 12.6)$ & $57.8( \pm 10.2)$ & $48.3( \pm 16.9)$ \\
\hline Eq1: Epley B 33 & $31.9( \pm 17.7)$ & $55.2( \pm 13.1)$ & $59.5( \pm 13.4)$ & $48.8( \pm 19.0)$ \\
\hline Eq2: Lombardi P34 & $31.5( \pm 17.4)$ & $53.3( \pm 12.4)$ & $58.5( \pm 12.9)$ & $47.8( \pm 18.4)$ \\
\hline Eq3: O'Connor $\mathrm{R}$ et al. ${ }^{35}$ & $30.5( \pm 16.9)$ & $52.2( \pm 12.3)$ & $56.7( \pm 12.6)$ & $46.5( \pm 18.0)$ \\
\hline Eq4: Mayhew J et al.36 & $32.2( \pm 17.8)$ & $54.8( \pm 12.8)$ & $59.8( \pm 13.3)$ & $48.9( \pm 18.9)$ \\
\hline Eq5: Brzycki M ${ }^{37}$ & $31.1( \pm 17.3)$ & $54.5( \pm 13.3)$ & $58.0( \pm 13.3)$ & $47.9( \pm 18.8)$ \\
\hline Eq6: Baechle $\mathrm{R}$ and Groves $\mathrm{R}^{38}$ & $32.0( \pm 17.7)$ & $55.7( \pm 13.4)$ & $59.8( \pm 13.5)$ & $49.2( \pm 19.2)$ \\
\hline
\end{tabular}

Abbreviations: 1RM, one-repetition maximum test; Eq, equation; HP, high paraplegia group; LP, low paraplegia group; TP, tetraplegia group. 
Table 3 Bland and Altman method and intraclass correlation coefficient (ICC) comparing 1RM test and current predictive equations for groups

\begin{tabular}{|c|c|c|c|c|c|c|c|c|c|c|c|c|c|c|c|c|}
\hline & \multicolumn{4}{|c|}{$T P$} & \multicolumn{4}{|c|}{$H P$} & \multicolumn{4}{|c|}{$L P$} & \multicolumn{4}{|c|}{ Total } \\
\hline & $M D$ & $\Delta$ & $I C C$ & $95 \% \mathrm{Cl}$ & $M D$ & $\Delta$ & $I C C$ & $95 \% \mathrm{Cl}$ & $M D$ & $\Delta$ & $I C C$ & $95 \% \mathrm{Cl}$ & $M D$ & $\Delta$ & $I C C$ & $95 \% \mathrm{Cl}$ \\
\hline \multicolumn{17}{|l|}{$1 R M$} \\
\hline Eq1 & 1.9 & 11.5 & $0.99 *$ & $0.96-1.00$ & -1.8 & 13.3 & $0.98^{*}$ & $0.93-0.99$ & -1.7 & 17.7 & $0.96^{*}$ & $0.88-0.99$ & -0.5 & 15.6 & $0.99 *$ & $0.98-0.99$ \\
\hline Eq2 & 2.3 & 9.9 & $0.99 *$ & $0.93-1.00$ & 0.1 & 9.6 & $0.99^{*}$ & $0.97-1.00$ & -0.8 & 15.6 & $0.97^{*}$ & $0.92-0.99$ & 0.5 & 12.8 & $0.99^{*}$ & $0.98-1.00$ \\
\hline Eq3 & 3.3 & 10.1 & $0.99 *$ & $0.73-1.00$ & 1.2 & 11.2 & $0.99^{*}$ & $0.96-1.00$ & 1.0 & 15.0 & $0.97^{*}$ & $0.92-0.99$ & 1.8 & 12.7 & $0.99^{*}$ & $0.97-1.00$ \\
\hline Eq4 & 1.6 & 10.6 & $0.99 *$ & $0.98-1.00$ & -1.5 & 10.9 & $0.99^{*}$ & $0.95-1.00$ & -2.0 & 16.8 & $0.96^{*}$ & $0.88-0.99$ & -0.6 & 14.3 & $0.99^{*}$ & $0.98-0.99$ \\
\hline Eq5 & 2.7 & 12.5 & $0.99 *$ & $0.91-1.00$ & -1.1 & 16.3 & $0.97^{*}$ & $0.92-0.99$ & -0.3 & 18.3 & $0.96^{*}$ & $0.89-0.99$ & 0.4 & 16.8 & $0.99^{*}$ & $0.97-0.99$ \\
\hline Eq6 & 1.8 & 12.2 & $0.99 *$ & $0.96-1.00$ & -2.3 & 14.6 & $0.97 *$ & $0.89-0.99$ & -2.0 & 18.6 & $0.96^{*}$ & $0.86-0.99$ & -0.9 & 16.7 & $0.99 *$ & 0-97-0.99 \\
\hline
\end{tabular}

Abbreviations: 1RM, one-repetition maximum test; Eq, equation (1: Epley B,33 2: Lombardi P, 34 3: O'Connor R et al., 35 4: Mayhew R et al., 36 5: Brzycki M; 37 6: Baechle R and Groves R, 38 , HP, high paraplegia group; LP, low paraplegia group; MD, mean difference (kg); TP, tetraplegia group; $\Delta$, range of the interval around the differences ( $\pm 1.96 \mathrm{s.d}$.).

Confidence interval was set on $95 \%(95 \% \mathrm{Cl})$.

${ }^{*} P \leqslant 0.016$.

The SPSS (version 22.0; IBM SPSS Statistics, Armonk, NY, USA) statistical package was used for the data processing. In the absence of multiple comparisons, statistical significance was set at $P<0.016$ (two-tailed).

\section{Statement of ethics}

We certify that all applicable institutional and governmental regulations concerning the ethical use of human volunteers were followed during the course of this research. The study was approved by the ethics committee of the Sarah Network of Rehabilitation Hospitals (number 13326213.7.0000.0022), and all patients provided written informed consent to participate in the study.

\section{RESULTS}

\section{Descriptive results}

All anthropometric and clinical variables, except time since injury, demonstrated no significant difference between groups. For the HP and LP groups, time since injury was statistically significantly different than that for the TP group (Table 1).

The HP and LP groups did not differ significantly regarding 1RM (kg), 4-12RM (kg), 4-12RM (repetitions), or relative strength (1RM divided by body mass) (Table 1). All these strength variables, except 4-12RM (repetitions) for the LP group, differed significantly between the TP group and the HP and LP groups (Table 1).

No injuries occurred during adaptation, familiarization and maximum strength tests.

\section{Current predictive equation analysis}

There were no significant differences between 1RM test and the current predictive equations (Table 2).

ICC values were significant and were classified as excellent for all five current predictive equation, for all groups (Table 3). Additionally, the Bland-Altman plot demonstrated that both the difference between the means and the intervals around these differences $( \pm 1.96$ times the s.d.) were small for all groups (Table 3).

The pdrestimated $1 \mathrm{RM}$ results for the tetraplegia group (Tables 2 and 3 and Figure 2). For the low paraplegia group, the predictive equation results were overestimated (Tables 2 and 3 and Figure 2). In Figure 2, there are points plotted over and under Bland-Altman's range limits for TP and LP, respectively.

For total group, the predictive equation of Brzycki (Eq5) $)^{37}$ had the lowest absolute mean difference compared to 1RM test (1RM vs $\mathrm{Eq} 5=0.4 \mathrm{~kg}$ ), but the highest interval range around the differences $(\Delta 1 \mathrm{RM}$ vs Eq5 $=16.8 \mathrm{~kg})$ (Table 3 and Figure 2). O'Connor et al. ${ }^{35}$ predictive equation (Eq3) presented the lowest interval range around the differences but the highest mean difference $(\Delta 1 \mathrm{RM}$ vs $\mathrm{Eq} 3=12.7$ and $1 \mathrm{RM}$ vs $\mathrm{Eq} 3=1.8 \mathrm{~kg}$, respectively) (Table 3 and Figure 2).
The predictive equation of Lombardi $(\mathrm{Eq} 2)^{34}$ presented the second best associated Bland-Altman results $(0.5 \mathrm{~kg}$ and $12.8 \mathrm{~kg}$ for mean difference and interval range around the differences, respectively) (Table 3 and Figure 2).

\section{Specific prediction equation}

The two equation models created for 1RM demonstrated a high R-square ( 0.972 and $0.973, P<0.01$, respectively) and low standard errors of the estimate for the measured $1 \mathrm{RM}(2.88 \mathrm{~kg}$ or $5.4 \%$ and $2.90 \mathrm{~kg}$ or $5.5 \%$ for models 1 and 2, respectively) (Table 4). The first model used only $4-12 \mathrm{RM}$ weight and repetitions; the second model also included the injury level (Table 4). For both equations, 4-12RM weight was the best predictor $(0.98$ and $0.99, P<0.01$, for models 1 and 2, respectively) (Table 4). Therefore, we opted for an equation with fewer predictors as follows because it is clinically easier to use:

$$
1 \mathrm{RM}=1.942+1.102 \times 4-12 \mathrm{RM}(\mathrm{kg})+0.414 \times 4-12 \mathrm{RM} \text { (repetitions) }
$$

\section{DISCUSSION}

Contrary to our initial hypothesis, current 1RM predictive equations can be used in individuals with spinal cord injuries to assess strength. The predictive equation of Lombardi ${ }^{34}$ presented the best associated cross-validity results. Additionally, an equation to predict 1RM strength based on the 4-12RM test for individuals with different levels of SCI was developed. The created predictive equation should be tested in order to verify whether it presents better accuracy than the current ones. The equation had a significant correlation with the 1RM test, and load was a better predictor than the number of repetitions.

Load is also the main predictor of other prediction equations. Whisemant et al. ${ }^{47}$ tested the validity of 11 prediction equations for $1 \mathrm{RM}$ and stated that increased equation precision is proportional to fewer repetitions and higher weight. Therefore, during the first attempt of the 4-12RM test, the researcher should estimate the initial load at 4 repetitions. This procedure will reduce error in the difference between the estimated result and the result obtained during the 1RM test.

Some studies have tested the validity of the prediction equations in other populations. ${ }^{26,28,31,32,48,49}$ Knutzen et al. ${ }^{32}$ tested four estimation equations in older men and women and verified that Brzycki equation was the one that presented the highest correlation coefficient for bench press $(\mathrm{r}=0.89)$. Nascimento et al. ${ }^{48}$ analyzed the validation of Brzycki equation and suggested that the equation can be performed to 

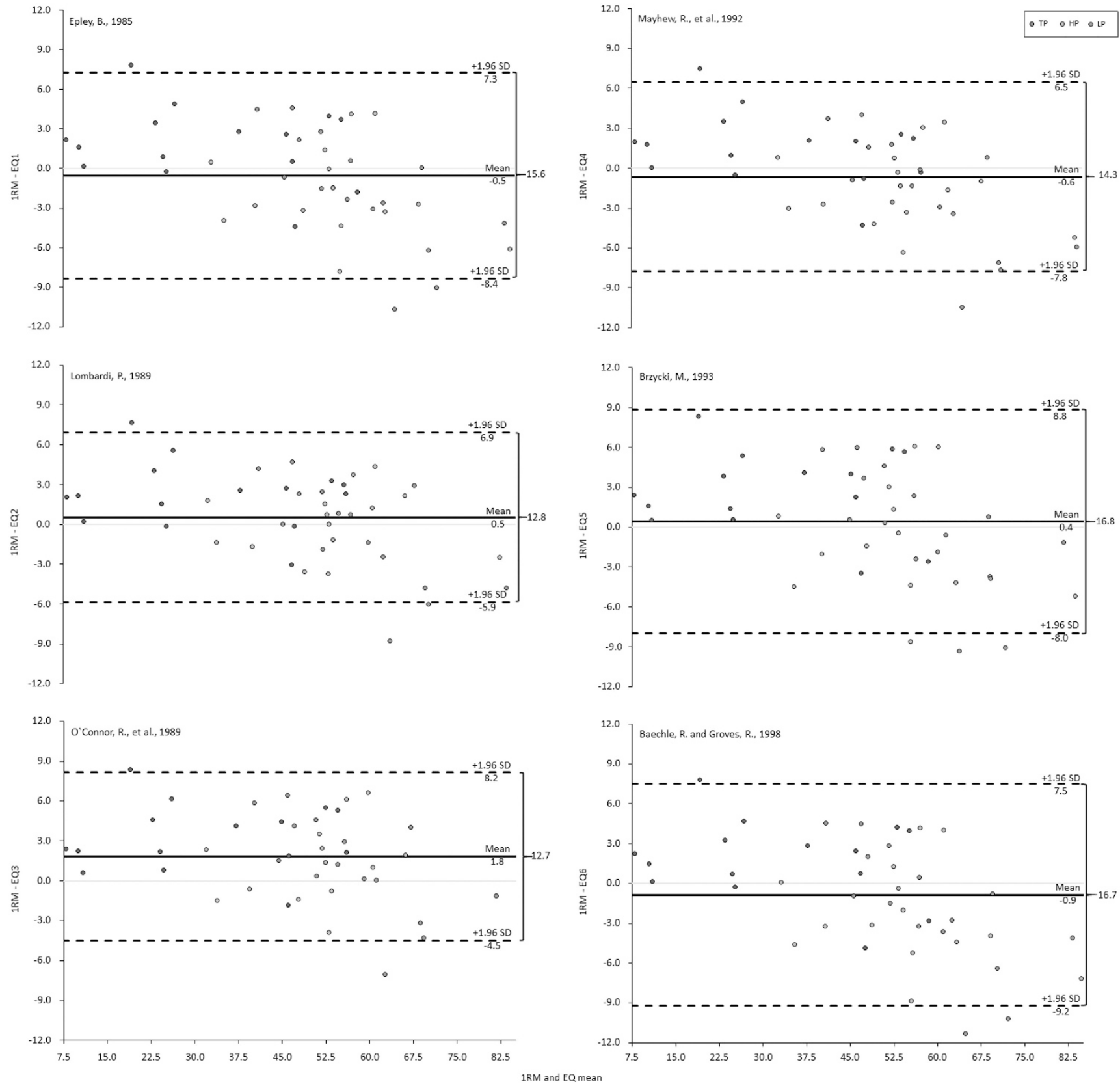

Figure 2 Bland and Altman method comparing 1RM test and current predictive equations for groups.1RM: one-repetition maximum test; EQ: equation; HP: high paraplegia group; LP: low paraplegia group; TP: tetraplegia group. A full colour version of this figure is available at the Spinal Cord journal online.

assess $1 \mathrm{RM}$ in the bench press. Menêses et al. ${ }^{49}$ otherwise, found that O'Connor equation produced the best estimation of 1RM for young adults with weight training experience.

In our study, all equations (Epley, ${ }^{33}$ Lombardi, ${ }^{34}$ O'Connor et al., ${ }^{35}$ Mayhew et al. ${ }^{36}$ Brzycki $^{37}$ and Baechle and Groves ${ }^{38}$ ) demonstrated the accurate and reliable data concerning bench press $1 \mathrm{RM}$ results in individuals with SCI. However, Lombardi ${ }^{34}$ has provided the best validity performance among them. Among the studies that have tested the validity of prediction equations, ${ }^{26,28,32,48,49}$ only Schwingel et al. ${ }^{26}$ used Lombardi's prediction equation. The authors tested the predictive equation with nine individuals with motor disabilities; ${ }^{26}$ however, none of them had SCI. The results showed that all predictive equations underestimated 1RM of bench press, and Lombardi's prediction equation had the highest mean difference $(\Delta=18.1 \mathrm{~kg}) .^{26}$ The tested subjects were international-level paralympic rowers, and the sample characteristics could have contributed for this difference. Nevertheless, the authors concluded that all tested equations were accurate. ${ }^{26}$

Although the current equations presented good accuracy, a new equation was created with the specific SCI population in order to be compared in future studies. All assessed groups had impairment or absence of leg strength and, therefore, reduced posture stabilization. Balance is worse for individuals with a higher injury level, such as the TP and HP groups, because of the reduced strength or absence of strength in the abdominal muscles. ${ }^{39,40}$ Individuals with injury higher than the $\mathrm{C} 7$ myotome have impairment of triceps muscle strength; therefore, their bench press maximum load was reduced. In addition, 
Table 4 R-square, adjusted $R^{2}$ values, $95 \% \mathrm{Cl}$ and standard error estimate for $1 \mathrm{RM}$ test, weights $(\boldsymbol{\beta})$ and probability values ( $p$ ) for significant predictors of 4-12RM (kg), 4-12RM (repetitions) and injury level

\begin{tabular}{|c|c|c|c|c|c|c|c|}
\hline & $\beta$ & $p$ & $95 \% \mathrm{Cl}$ & $R^{2}$ & Adjusted $\mathrm{R}^{2}$ & $S E E$ & SEE (\%) \\
\hline \multicolumn{8}{|l|}{ Model 1} \\
\hline 4-12 RM (kg) & 0.98 & $<0.01$ & $1.04-1.16$ & 0.972 & 0.971 & 2,88 & 5,4 \\
\hline 4-12 RM (repetitions) & 0.05 & 0.04 & $0.02-0.81$ & & & & \\
\hline Injury Level & - & - & - & & & & \\
\hline \multicolumn{8}{|l|}{ Model 2} \\
\hline 4-12 RM (kg) & 0.99 & $<0.01$ & $1.04-1.19$ & 0.973 & 0.971 & 2,90 & 5,5 \\
\hline 4-12 RM (repetitions) & 0.05 & 0.04 & $0.02-0.82$ & & & & \\
\hline Injury Level & -0.02 & 0.58 & $-1.71-0.98$ & & & & \\
\hline
\end{tabular}

Abbreviations: 1RM, one-repetition maximum test; 4-12RM, 4 to 12 repetition maximum test; SEE, standard error of estimate.

Model 1 includes two predictors as follows: repetitions and weight of $4-12 \mathrm{RM}$ test. On model 2, spinal cord injury level was added. Confidence interval was set on $95 \%$ (95\% CI).

the impaired trunk balance, reduced upper limb strength and absence of leg strength ${ }^{39,40}$ could alter posture stabilization and correct positioning, and, consequently, could influence the test results. Therefore, further studies must test the specific predictive equation of the present study with another data set of individuals with SCI in order to confirm the internal validation of the results. Moreover, it would be important to determine the cross-validity of such a prediction equation compared to a gold standard (e.g., dynamometer isokinetic strength test). It also should be tested with female subjects with different SCI levels.

The present study sample had individuals who were not participating in physical activities before rehabilitation program. Even with a novice strength training population, there were no injuries reported by the patients, during any training sessions and assessments. Some authors have reported an increased risk of injury, ${ }^{19,25-27}$ although their studies did not demonstrate incidence of injuries during tests' procedure. Therefore, the 1RM test, performed correctly, can be considered a safe strength assessment for individuals with SCI.

Some studies have revealed that generalized prediction equations are not applicable to specific populations, ${ }^{50,51}$ however, the present study results showed that for individuals with SCI, the tested $1 \mathrm{RM}$ prediction equations are accurate for bench press. It is important to note that the pectoralis major, brachial triceps and deltoids are the primary muscles used during bench press exercises. This movement pattern has limitations when generalizing other tests of movement or functional independence.

\section{Study limitations}

The weight range $(0.5-20 \mathrm{~kg})$ was not sensitive enough to adequately adjust the load for individuals with higher lesion levels (TP). Lower weights should be used for more precise 1RM testing results for this specific group. Other study limitation was that the same tester assessed both $1 \mathrm{RM}$ and $4-12 \mathrm{RM}$, i.e., the tester was not blinded of the maximum strength tests.

\section{CONCLUSION}

This study concluded that all $1 \mathrm{RM}$ predictive equations used in this study are accurate to assess individuals with SCI at the bench press exercise. However, the predictive equation of Lombardi presented the best-associated cross-validity results. A specific prediction equation to determine 1RM based on 4-12RM test in individuals with spinal cord injury was also proposed. Results of 1RM have practical value for allied health professionals in assessing and prescribing strength training programs. It is important to have an easy, non-expensive, safe and practical strength test for spinal cord injured individuals for clinical use during a rehabilitation program. Future studies could be conducted to determine the cross-validity of the elaborated prediction equation comparing it to a gold standard (for example, dynamometer isokinetic strength test).

\section{DATA ARCHIVING}

There were no data to deposite.

\section{CONFLICT OF INTEREST}

The authors declare no conflict of interest.

\section{ACKNOWLEDGEMENTS}

We thank the Physical Education staff of Sarah Rehabilitation Hospital Network who provided us with support and assistance for the development of this research. We certify that no party has a direct interest in the results of the research supporting this article or has or will confer benefit on us or on any organization with which we are associated.

1 Hicks AL, Martin KA, Pelletier CA, Ditor DS, Foulon B, Wolfe DL. The effects of exercise training on physical capacity, strength, body composition and functional performance among adults with spinal cord injury: a systematic review. Spinal Cord 2011; 49: 1103-1127.

2 Turbanski S, Schmidtbleicher D. Effects of heavy resistance training on strength and power in upper extremities in wheelchair athletes. J Strength Cond Res 2010; 24: 8-16.

3 Ribeiro FN, Gentil P. The effects of resistance training intervention in the rehabilitation of patients with spinal cord injury: a literature review. Acta Fisiatr 2011; 18: 91-96.

4 Bar-On ZH, Nene AV. Relationship between heart rate and oxygen uptake in thoracic level paraplegics. Paraplegia 1990; 28: 87-95.

5 Mulroy SJ, Gronley JK, Newsam CJ, Perry J. Electromyographic activity of shoulder muscles during wheelchair propulsion by paraplegic persons. Arch Phys Med Rehabil 1996; 77: 187-193.

6 Perry J, Gronley JK, Newsam CJ, Reyes ML, Mulroy SJ. Electromyographic analysis of the shoulder muscles during depression transfers in subjects with low-level paraplegia. Arch Phys Med Rehabil 1996; 77: 350-355.

7 Cooney MM, Walker JB. Hydraulic resistance exercise benefits cardiovascular fitness of spinal cord injured. Med Sci Sports Exerc 1986; 18: 522-525.

8 Jacobs PL, Nash MS, Rusinowski JW. Circuit training provides cardiorespiratory and strength benefits in persons with paraplegia. Med Sci Sports Exerc 2001; 33: 711-717.

9 Figoni SF. Exercise responses and quadriplegia. Med Sci Sports Exerc 1993; 25: 433-441.

10 Wilmore JH, Costill DL, Kenney WL. Physiology of Sport and Exercise, 4th edn. Human Kinetics Publishers: Champaign, IL, USA. 2007.

11 Mukherjee G, Samanta A. Energy cost and locomotor performance of the low-cost arm-lever-propelled three-wheeled chair. Int J Rehabil Res 2001; 24: 245-249.

12 Nash MS, van de Ven I, van Elk N, Johnson BM. Effects of circuit resistance training on fitness attributes and upper-extremity pain in middle-aged men with paraplegia. Arch Phys Med Rehabil 2007; 88: 70-75.

13 Davies HT, Crombie IK. Getting to grips with systematic reviews and meta-analyses. Hosp Med 1998; 59: 955-958. 
14 Hicks AL, Martin KA, Ditor DS, Latimer AE, Craven C, Bugaresti J et al. Long-term exercise training in persons with spinal cord injury: effects on strength, arm ergometry performance and psychological well-being. Spinal Cord 2003; 41: 34-43.

15 Mojtahedi MC, Valentine RJ, Evans EM. Body composition assessment in athletes with spinal cord injury: comparison of field methods with dual-energy X-ray absorptiometry. Spinal Cord 2009; 47: 698-704.

16 Maggioni M, Bertoli S, Margonato V, Merati G, Veicsteinas A, Testolin G. Body composition assessment in spinal cord injury subjects. Acta Diabetol 2003; 40 (Suppl 1): S183-S186.

17 Jones LM, Goulding A, Gerrard DF. DEXA: a practical and accurate tool to demonstrate total and regional bone loss, lean tissue loss and fat mass gain in paraplegia. Spinal Cord 1998; 36: 637-640.

18 Gorgey AS, Shepherd C. Skeletal muscle hypertrophy and decreased intramuscular fat after unilateral resistance training in spinal cord injury: case report. J Spinal Cord Med 2010; 33: 90-95.

19 Kim PS, Mayhew JL, Peterson DF. A modified YMCA bench press test as a predictor of 1 repetition maximum bench press strength. J Strength Cond Res 2002; 16: 440-445.

20 Ratamess NA, Alvar BA, Evetoch TK, Housh TJ, Kibler WB, Kraemer WJ et al. American College of Sports Medicine position stand. progression models in resistance training for healthy adults. Med Sci Sports Exerc 2009; 41: 687-708.

21 Garber CE, Blissmer B, Deschenes MR, Franklin BA, Lamonte MJ, Lee IM et al. American College of Sports Medicine position stand. Quantity and quality of exercise for developing and maintaining cardiorespiratory, musculoskeletal, and neuromotor fitness in apparently healthy adults: guidance for prescribing exercise. Med Sci Sports Exerc 2011; 43: 1334-1359.

22 Dwyer GB, Davis SE, Pire NI, Thompson WR. ACSM's Health-Related Physical Fitness Assessment Manual, 4th edn. Lippincott Williams \& Wilkins: Philadelphia, PA, USA. 2010.

23 Thompson WR, Gordon NF, Pescatello LS. ACSM's Guidelines for Exercise Testing and Prescription, 8th edn. Lippincott Williams \& Wilkins: Philadelphia, PA, USA. 2009.

24 Brown LE, Weir JP. ASEP Procedures Recommendation I: accurate assessment of muscular strength and power. J Exerc Physiol 2001; 4: 1-21.

25 Abadie BR, Altorfer GL, Schuler PB. Does a regression equation to predict maximal strength in untrained lifters remain valid when the subjects are technique trained? J Strength Cond Res 1999; 13: 259.

26 Schwingel PA, Porto YC, Dias MC, Moreira MM, Zoppi CC. Predicting one repetition maximum equations accuracy in paralympic rowers with motor disabilities. J Strength Cond Res 2009; 23: 1045-1050.

27 Reynolds JM, Gordon TJ, Robergs RA. Prediction of one repetition maximum strength from multiple repetition maximum testing and anthropometry. J Strength Cond Res 2006; 20: 584 .

28 Lacio ML, Damasceno VO, Vianna JM, Lima JRP, Reis VM, Brito JP et al. Precision of 1-RM prediction equations in non-competitive subjects performing strength training. Motricidade 2010; 6: 31-37.

29 Dohoney P, Chromiak JA, Lemire D, Abadie B, Kovacs C. Prediction of one repetition maximum (1-RM) strength from a 4-6 RM and a 7-10 RM submaximal strength test in healthy young adult males. J Exerc Physiol. Online 2002; 5: 54-59.

30 Simpson SR, Rozenek R, Garhammer J, Lacourse M, Storer T. Comparison of one repetition maximums between free weight and universal machine exercises. J Strength Cond Res 1997; 11: 103-106.
31 LeSuer DA, McCormick JH, Mayhew JL, Wasserstein RL, Arnold MD. The accuracy of prediction equations for estimating 1-RM performance in the bench press, squat, and deadlift. J Strength Cond Res 1997; 11: 211.

32 Knutzen KM, Brilla LR, Caine D. Validity of 1 RM prediction equations for older adults. J Strength Cond Res 1999; 13: 242-246.

33 Epley B. Poundage Chart. Boyd Epley Workout. Body Enterprises: Lincoln, NE, USA. 1985.

34 Lombardi VP. Beginning Weight Training: the Safe and Effective Way. WC Brown: Dubuque, IA, USA, 1989.

35 O'Connor R, Simmons J, O'Shea P. Weight Training Today. West Publishing: St Paul, MN, USA. 1989.

36 Mayhew JL, Ball TE, Arnold MD, Bowen JC. Relative muscular endurance performance as a predictor of bench press strength in college men and women. J Strength Cond Res 1992; 6: 200.

37 Brzycki M. Strength testing-predicting a one-rep max from reps-to-fatigue. J Phys Educ Rec Dan 1993; 64: 88-90.

38 Baechle TR, Groves BR. Weight Training: Steps to Success, 2nd edn Human Kinetics Publishers: Champaign, IL, USA. 1998.

39 Kirshblum SC, Burns SP, Biering-Sorensen F, Donovan W, Graves DE, Jha A et al. International standards for neurological classification of spinal cord injury (revised 2011). J Spinal Cord Med 2011; 34: 535-546.

40 Kirshblum SC, Waring W, Biering-Sorensen F, Burns SP, Johansen M, Schmidt-Read M et al. Reference for the 2011 revision of the International Standards for Neurological Classification of Spinal Cord Injury. J Spinal Cord Med 2011; 34: 547-554.

41 Ribeiro FN, Lopes GH. Body composition modifications in people with chronic spinal cord injury after supervised physical activity. J Spinal Cord Med 2011; 34: 586-593.

42 Bulbulian R, Johnson RE, Gruber JJ, Darabos B. Body composition in paraplegic male athletes. Med Sci Sports Exerc 1987; 19: 195-201.

43 Ribeiro FN, Lopes GH. Analysis of body composition values in men with different spinal cord injury levels. Fisioter Mov 2013; 26: 743-751.

44 Spungen AM, Bauman WA, Wang J, Pierson RN Jr. Measurement of body fat in individuals with tetraplegia: a comparison of eight clinical methods. Paraplegia 1995; 33: 402-408.

45 Dias RMR, Cyrino ES, Salvador EP, Caldeira LFS, Nakamura FY, Papst RR et al. Influence of familiarization process on muscular strength assessment in 1-RM tests. Rev Bras Med Esporte 2005; 11: 34-38.

46 Cicchetti DV. Guidelines, criteria, and rules of thumb for evaluating normed and standardized assessment instruments in psychology. Psychol Assessment 1994; 6: 284.

47 Whisenant MJ, Panton LB, East WB, Broeder CE. Validation of submaximal prediction equations for the 1 repetition maximum bench press test on a group of collegiate football players. J Strength Cond Res 2003; 17: 221-227.

48 Nascimento MAd, Cyrino ES, Nakamura FY, Romanzini M, Pianca HJC, Queiróga MR. Validation of the Brzycki equation for the estimation of 1-RM in the bench press. Rev Bras Med Esporte 2007; 13: 47-50.

49 Menêses A, Santana F, Soares A, Souza B, Souza D, Santos M et al. Validity of one repetition maximum predictive equations vary according to the exercise performed in trained young adults. Rev Bras Ativ Fis Sau 2013; 18: 95-104.

50 Becque DM, Pick J. Validity of predicting $1 \mathrm{RM}$ and \% $1 \mathrm{RM}$ in weight-trained and untrained males. Med Sci Sports Exerc 1995; 27: S210.

51 Braith RW, Graves JE, Leggett SH, Pollock ML. Effect of training on the relationship between maximal and submaximal strength. Med Sci Sports Exerc 1993; 25: $132-138$. 